\title{
Comparison of Touch Sensation among Congenital Blind, Early Onset Blind, and Late Onset Blind, Using Moberg's Test
}

\author{
Swapnil Subhashrao Bhirange ${ }^{1}$, Chitra Pillai² \\ ${ }^{1}$ Department of Physiology, Jawaharlal Nehru Medical College, Sawangi (Meghe), Wardha, Maharashtra, \\ India, ${ }^{2}$ Department of Physiology, Topiwala National Medical College, Mumbai Central, Mumbai, \\ Maharashtra, India.
}

\section{ABSTRACT}

\section{BACKGROUND}

The objectives of the study were to assess and compare touch sensation of dominant and non-dominant hands among blind since birth, early onset blind \& late onset blind participants using Moberg's test and determine if the time of onset of blindness affected the touch sensation.

\section{METHODS}

50 blind participants from various colleges in Mumbai were assessed. Detailed history about onset of blindness, motor dominance etc. of blind was asked. Participants were instructed to pick up objects (suggested by Moberg) one at a time, as fast as possible, and place them into a box using dominant and non-dominant hands alternatively. Kruskal Wallis Test was used for analysis.

\section{RESULTS}

Average values of Moberg's test of dominant \& non - dominant hands of blind since birth versus late onset blind were statistically significant and those of early onset blind versus late onset blind were statistically significant. Average values of Moberg's test of blind since birth versus early onset blind were not statistically significant. Thus touch sensation was improved more in blind since birth \& early onset blind compared to late onset blind participants.

\section{CONCLUSIONS}

Thus we conclude that in the absence of visual stimuli, touch sensation in blind since birth and early onset blind is improved compared to late onset blind participants.

\section{KEY WORDS}

Blind, Cross - Modal Synaptic Plasticity, Substitution of Sense. Moberg's Pick - up Test, Critical Period
Corresponding Author:

Dr. Swapnil Subhashrao Bhirange,

Gajanan Nagar, Arvi Naka,

Ward No. 8, Wardha,

Maharashtra, India.

E-mail: swapnilbhirange3@gmail.com

DOI: $10.14260 / j e m d s / 2021 / 659$

How to Cite This Article:

Bhirange SS., Pillai C. Comparison of touch sensation among congenital blind, early onset blind, and late onset blind, using Moberg's test. J Evolution Med Dent Sci 2021;10(37):3247-3251, DOI: 10.14260/jemds/2021/659

Submission 26-05-2021,

Peer Review 05-08-2021,

Acceptance 13-08-2021,

Published 13-09-2021.

Copyright (c) 2021 Swapnil Subhashrao Bhirange et al. This is an open access article distributed under Creative Commons Attribution License [Attribution 4.0 International (CC BY 4.0)] 


\section{BACKGROUND}

Functional independence in performance of activities of daily life requires skilled hand motor control and the tactile sensibility of fingers appropriately assisted by other special senses like eyes, ears etc. The tactile sensibility of fingers based on cutaneous mechanoreceptors play a crucial role in providing such information. It is estimated that about 75 million people around the world would be visually impaired by the end of year 2020.1 Thus it is important to understand how brain works by understanding the key role of neuronal changes, neuronal rewiring if that particular sense is absent. It gives an insight in developing new treatment alternatives.

Human brain is a mystery for the neuroscientist as the functioning of a particular area for a particular ability goes beyond the known boundaries of that particular area of the brain. This suggests the dynamic functional adaptability of the brain. This ability can be called as neuroplasticity of the brain which works through formation of new synapses or rearranging the existing synapses.2,3,4 Neuroplasticity can be achieved through multiple stimulation as in passive repetitive movements, learning new tasks, or sensory deprivation. ${ }^{5}$

Blind individuals do not have the advantage of vision to perceive the external world. Hence, they depend on other special senses to be aware of the external world. Blind people use touch sensation as a source of continuous similar information, substitute to vision in sighted subjects, in dayto-day life. ${ }^{6}$ Thus optical information in sighted subjects can be extrapolated to the tactile information in blind subjects to say that blind are seeing, highlighting the behavioural equivalence. Blind also exhibit relevant anticipatory behaviour, for example, anticipating the movement of hands and limbs to overcome the obstacle while walking. This is consistent with 'preafference and reafference' of Freeman ${ }^{7}$ or Intentional arc of Merlou Ponty ${ }^{8}$ or controlled synesthesia of Hurley and Noe. "Moberg's pick-up test" is one of the tools which was devised by Eric Moberg to assess the tactile gnosis, especially the sensitivity present in the fingertips which allows a significant awareness of the outside world. ${ }^{10}$ In this test, the subject is asked to pick up a number of objects of different sizes and shapes, placed on the table and to put them as quickly as he / she can into a box, first with one hand (preferably the dominant hand) and then with the other (non - dominant hand).

\section{Objectives}

1. Assessment and comparison of touch sensation of dominant and non- dominant hands among blind since birth, early onset blind \& late onset blind participants using of Moberg's test and highlighting the substitution of senses associated with cross modal and multimodal neuroplasticity.

2. To determine if the time of onset of blindness affects the enhancement of touch sensation.

\section{Materials}

Moberg's Pick - up test materials include

1. $60 \times 30 \mathrm{~cm}$ Plastic desk - blotter,

2. $3 \times 8 \times 5 \mathrm{~cm}$ box
3. 12 small metallic objects [ $5 \mathrm{~cm}$ fine screw, $2.3 \mathrm{~cm}$ wide screw, 3.3 and $2.8 \mathrm{~cm}$ paper clips, $1.4 \mathrm{~cm}$ diameter ring, $3.8 \mathrm{~cm}$ safety pin, two (2) small nuts, one (1) wing nut, $2.8 \mathrm{~cm}$ and $2.2 \mathrm{~cm}$ diameter coins, $5.5 \mathrm{~cm} \mathrm{key]}$

4. Stopwatch

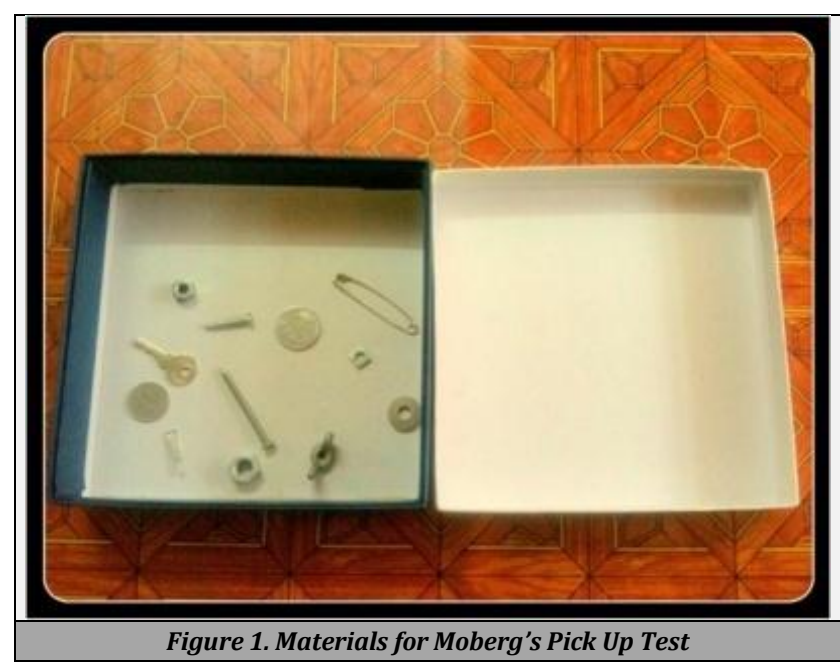

\section{METHODS}

In this comparative cross-sectional study, 50 blind participants from Kamla Mehta Dadar School, Mumbai were assessed. Institutional Ethics committee approval was taken. Study duration was of 6 months from 2014 June to 2014 December. Detailed history about onset of blindness, motor dominance etc. of blind was noted. Participants having an onset of blindness since birth were congenital blind. On the other hand, participants having an onset of blindness within the first 8 years of life were early onset blind, while participants having an onset after 8 years of life were late onset blind. ${ }^{11}$

In the Moberg pick - up test, the patient was positioned in the sitting position in a chair and a table was put in front of the patient, and 12 small objects (as mentioned above) were put on the table. ${ }^{12}$ Participants were instructed to pick them up one at a time, as fast as possible, and place them into a box without sliding on the surface and the duration was recorded in seconds. The test was done using dominant hand first \& repeated with non-dominant hand. Inclusion criteria was willingness of the participants to participate in the study and give consent to perform the test. Exclusion criteria included that the participants were apparently healthy without any deformity of upper extremities, and without any subjective sensory or motor complaints in the upper extremities like tingling, numbness, and weakness, any known peripheral neuropathy or any chronic illnesses and taking treatment for the same, on cough suppressant (sedatives), alcohol intake and less than six hours of sleep.

\section{Statistical Analysis}

For comparing the values of Moberg's test of dominant and non - dominant hands in various groups of blind participants, Kruskal Wallis Test by rank (One way analysis of variance ANOVA), was used. 


\section{RESULTS}

\begin{tabular}{|c|c|c|c|c|}
\hline $\begin{array}{c}\text { Moberg's } \\
\text { Pick - Up Test }\end{array}$ & $\begin{array}{c}\text { Blind since } \\
\text { birth } \\
\text { Mean Time } \pm \\
\text { SD (seconds) }\end{array}$ & $\begin{array}{l}\text { Early Onset } \\
\quad \text { Blind } \\
\text { Mean Time } \pm \\
\text { SD (seconds) }\end{array}$ & $\begin{array}{c}\text { Late Onset } \\
\text { Blind } \\
\text { Mean Time } \pm \\
\text { SD (seconds) }\end{array}$ & P Value \\
\hline Dominant Hand & $19.89 \pm 1.948$ & $22.00 \pm 2.673$ & $32.44 \pm 5.341$ & $P<0.001$ \\
\hline $\begin{array}{c}\text { Non - Dominant } \\
\text { Hand }\end{array}$ & $22.00 \pm 2.434$ & $24.93 \pm 3.432$ & $36.89 \pm 5.533$ & $\mathrm{P}<0.001$ \\
\hline
\end{tabular}

Average values of Moberg's test of dominant hand \& nondominant hand -

1. Blind since birth (dominant $19.89 \pm 1.948$ \& non dominant $22.00 \pm 2.434$ ) versus late onset blind (dominant $32.44 \pm 5.341$ \& non-dominant $36.89 \pm 5.533$ ) $(\mathrm{P}<0.001)$

2. Early onset blind (dominant $22.00 \pm 2.673$ \& non dominant $24.93 \pm 3.432$ ) versus late onset blind (dominant $32.44 \pm 5.341$ \& non-dominant $36.89 \pm 5.533$ ) $(\mathrm{P}<0.001)$

3. Blind since birth (dominant $19.89 \pm 1.948$ \& nondominant $22.00 \pm 2.434$ ) versus early onset blind (dominant $22.00 \pm 2.673$ \& non dominant $24.93 \pm 3.432$ ) $(\mathrm{P}<0.15)$

4. We conclude that Moberg's test is positive in blind since birth \& early onset blind $(\mathrm{P}<0.01)$ compared to late onset participants.

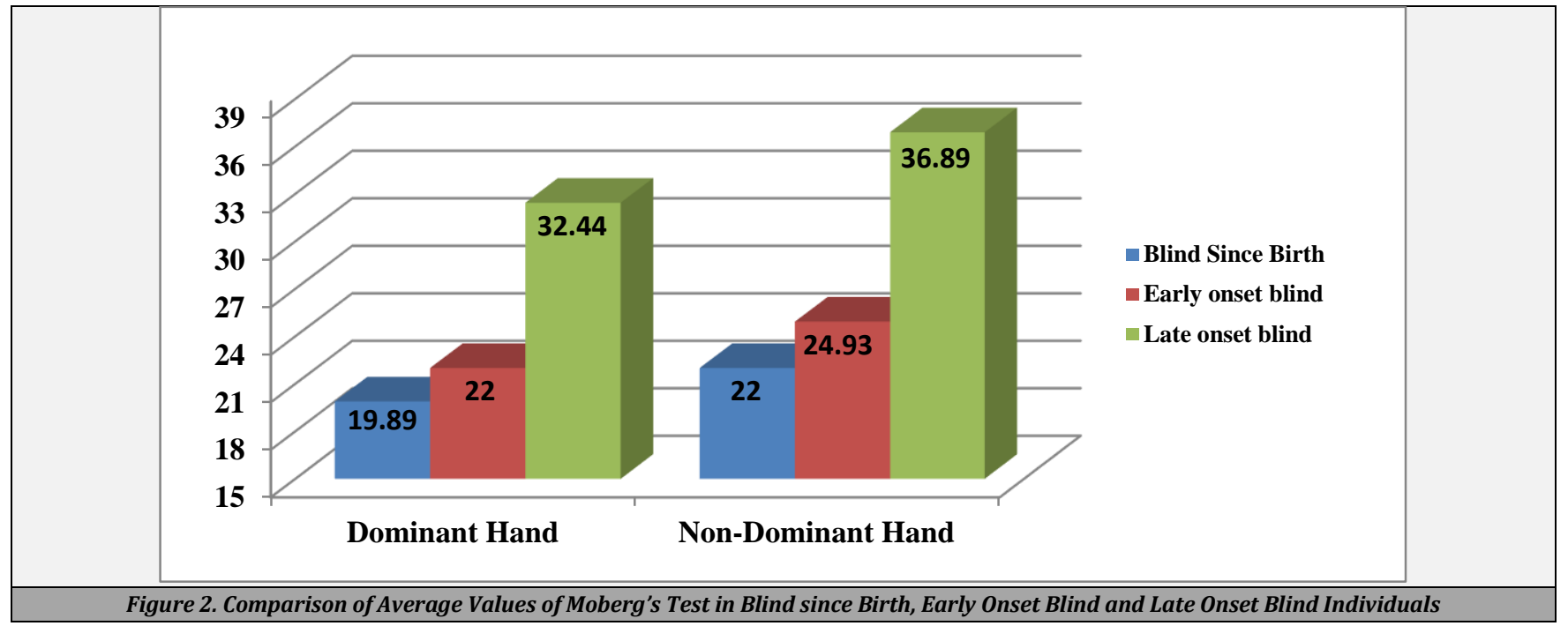

\section{DISCUSSION}

Our data shows an increased sensitivity to touch in blind since birth \& early onset blind participants than in late onset blindness. Normal people acknowledge and process objects with the help of their visual attributes in sensory specific areas like visual cortex. ${ }^{13}$ Ventrolateral posterior nucleus (VPN) or intralaminar nuclei plays an important role as control centre for processing sensory information (touch, pain, pressure, temperature, and vibrations). Primary somatosensory area in the parietal lobe of cerebral cortex mainly processes and sorts out the tactile information conveyed by VPN and the information is then sent to the secondary somatic sensory cortex or to the other areas of the brain. ${ }^{14}$ Rapidly adapting receptors in the skin (Meissner's corpuscles) and subcutaneous tissue (Pacinian corpuscles) provide essential information during an active touch (perception or finger swiping to determine the roughness or smoothness of the surface) and help in segregating various articles (as while performing the Moberg's test). ${ }^{15}$

Brain is efficiently able to reorganize and recompense for the shortfall in individuals with inborn or acquired absence of a sensory modality. ${ }^{13,16}$ When information acquired with one sensory modality is used to accomplish a task which is normally sub - served primarily by another sensory modality is called as cross modal plasticity. ${ }^{17}$ Neuroplasticity can be considered as a potential of the neurons to generate new connections and tracks with new jobs in the cortex leading to reformation. ${ }^{18}$ This change occurs at the level of molecular, microarchitectural and functional organization or even reframe itself as normal development / maturation of the body progress, as a response to experience, attainment of new skills, acquisition or deprivation of certain sensory stimulation, and even to the injury. ${ }^{19}$ Thus areas of the brain dispossessed off committed sensory stimulations can be utilized by other sensory modalities. ${ }^{20}$

Cross modal plasticity in blind develops rapidly. The occipital cortex is a part of functional neural network for tactile discrimination in conjugation with the posterior parietal cortex. ${ }^{17}$ Visual cortex in the blind people processes the sensory information including the tactile stimuli from other sensory modality and assign them with meaningful rhetorical and semantic properties. ${ }^{21}$ There is a critical period (birth to approximately 16 yrs of age) for reorganization of the primary visual cortex to function during tactile discrimination tasks. ${ }^{17,22}$ There is a surge in synaptic connections in the visual cortex starting from the seventh month of pregnancy up to birth and two months after the birth. An expansion by almost tenth occurred between second and fourth month. This has been connected to capability to generate three-dimensional images and enhancement in child's vision during that age. The synapses extend to its maximum number around eight months of age, persevering up to the age of four years, and a gradual decline occurred thereafter. ${ }^{23}$ The dendritic branches of the 
remaining synapses in the visual cortex keep increasing and budding, thereby creating new synapses. By patching one of the kittens' eyes right after birth, for three months, they discovered that the kittens were blind although the visual apparatus of the patched eye was not damaged. Visual deficiency in the beginning of life changed the cortex to receive visual impulses only from the unpatched eye. ${ }^{24}$ The mentioned principle applies to humans as well, although the critical period is longer. If the child does not receive any visual stimulation between the ages of eight and ten, it will result in blindness. Hence blindness from an early age can cause visual cortex to be recruited in somatosensory processing till the age of 16 years but probably not after that. Occurrence of an association between touch and visual area can be established by the evidences that as the age of blindness is less (as in blind since birth and early blind individuals) the activity in the post central gyrus and the posterior parietal cortex keep on increasing with a relative decrease in the activity of secondary somatosensory area. ${ }^{22}$ It is found that the visual cortex of early blind are thicker than the late blind and non - blind suggests that the lack of visual stimulation (as in case of blind since birth and early blind) increases the number of functional synapses in the visual cortex thus proves the increased expressive capability of the visual cortex. ${ }^{25,26}$

Also, the increased sensitivity to touch sensation in blind since birth \& early onset blind participants has been inclined with activation of primary visual cortex, degree of visual proficiency during the sensitive visual period and differential recruitment of visual cortical pathways. ${ }^{27}$ The visual cortex in congenital blind is redistributed to process tactile, spatial and somatosensory information and even language. It is to be remembered, though, the visual network in blind since birth subjects will evolve and reinforce only if exposed to relevant events and activities related to age as well as alter other senses in compensation for blindness. Thus, it is obvious that the range of plastic recognition varies individual to individual. ${ }^{28}$

\section{CONCLUSIONS}

Thus, we conclude that the touch sensation was much improved in individuals who were blind since birth compared to early onset blind better than the late onset blind individuals. The probable reason for early recruitment of visual cortex for enhancement of touch sensation is by the mechanism of cross modal synaptic plasticity in individuals who are blind since birth and early onset blind individuals compared to late onset blind. Further studies are required to establish the mechanism of increased touch sensitivity which will be helpful to manage the disability.

Data sharing statement provided by the authors is available with the full text of this article at jemds.com.

Financial or other competing interests: None.

Disclosure forms provided by the authors are available with the full text of this article at jemds.com.

We are thankful to Dr. Nisha Thakkar, (MSc, PhD, Yoga Teacher) who helped us in recruiting the blind individuals and duly carrying out the project. We also thank the staff of Department of Physiology, TNMC \&
BYL Nair Ch. Hospital, Mumbai Central, Mumbai for helping us in all the possible way.

\section{REFERENCES}

[1] Pascolini D, Mariotti SP. Global estimates of visual impairment: 2010. Br J Ophthalmol 2012;96(5):614-8.

[2] Bach-y-Rita P. Brain plasticity as a basis for recovery of function in humans. Neuropsychologia 1990;28(6):54754.

[3] Bach-y-Rita P. Theoretical basis for brain plasticity after a TBI. Brain Injury 2003;17(8):643-51.

[4] Bavelier D, Neville HJ. Cross - modal plasticity: where and how? Nat Rev Neurosci 2002;3(6):443-52.

[5] Bach-y-Rita P, Kercel SW. Sensory substitution and the human-machine interface. Trends Cogn Sci 2003;7(12):541-6.

[6] Gagnon L, Schneider FC, Siebner HR, et al. Activation of the hippocampal complex during tactile maze solving in congenitally blind subjects. Neuropsychologia 2012;50(7):1663-71.

[7] Kay LM. How brains create the world: the dynamical legacy of Walter J Freeman in olfactory system physiology. Chaos Complex Lett 2017;11(1):41-7.

[8] Merleau-Ponty M. Phenomenology of Perception. Translated by Colin Smith. London: Rortledge and Kegan Paul 1962: p. 98.

[9] Hurley S, Noë A. Neural plasticity and consciousness. Biology and Philosophy 2003;18:131-68.

[10] Moberg E. Objective methods for determining the functional values of sensibility in the hand. The Journal of Bone and Joint Surgery 1958;40-B(3):454-76.

[11] Burr D, Gori M. Multisensory integration develops late in humans. Chap - 18. In: Murray MM, Wallace MT, eds. The neural bases of multisensory processes. Boca Raton (FL): CRC Press/ Taylor \& Francis 2012.

[12] Wong MS, Griffith JF, Hui ACF, et al. Discriminatory sonographic criteria for the diagnosis of carpal tunnel syndrome. Arth Rheum 2002;46(7):1914-21.

[13] Merabet LB, Pascual-Leone A. Neural reorganization following sensory loss: the opportunity of change. Nat Rev Neurosci 2010;11(1):44-52.

[14] Raju H, Tadi P. Neuroanatomy, somatosensory cortex. In: StatPearls. Treasure Island (FL): StatPearls Publishing 2020 Jan. [Updated 2020 Nov 19].

[15] Purves D, Augustine GJ, Fitzpatrick D, et al. Neuroscience. The nociceptive components of the thalamus and cortex. $2^{\text {nd }}$ edn. Sunderland (MA): Sinauer Associates 2001.

[16] Ricciardi E, Pietrini P. New light from the dark: what blindness can teach us about brain function? Curr Opin Neurol 2011;24(4):357-63.

[17] Cohen LG, Celnik P, Pascual-Leone A, et al. Functional relevance of cross-modal plasticity in blind humans. Nature 1997;389(6647):180-3.

[18] Sharma N, Classen J, Cohen LG. Neural plasticity and its contribution to functional recovery. Handb Clin Neurol 2013;110:3-12.

[19] Kolb B, Gibb R. Brain plasticity and behavior in the developing brain. J Can Acad Child Adolesc Psychiatry 2011;20(4):265-76. 
[20] Follmann R, Goldsmith CJ, Stein W. Multimodal sensory information is represented by a combinatorial code in a sensorimotor system. PLoS Biol 2018;16(10):e2004527.

[21] Georgetown University Medical Center. People blind from birth use visual brain area to improve other senses: can hear and feel with greater acuity. Science Daily. Oct 10, 2010. Retrieved January 24, 2021.

[22] Cohen LG, Week RA, Sadaro N, et al. Period of susceptibility for cross-modal plasticity in blind. Ann Neurol 1999;45(4):451-60.

[23] Sadato N, Okada T, Honda M, et al. Critical period for cross - modal plasticity in blind humans: a functional MRI study. NeuroImage 2002;16(2):389-400.
[24] Hubel DH, Wiesel TN. Effects of monocular deprivation in kittens. Naunyn Schmiedebergs Arch for Exp Pathol Pharmakol 1964;248:492-7.

[25] Huttenlocher PR, de Courten C. The development of synapses in striate cortex of man. Hum Neurobiol 1987;6(1):1-9.

[26] Jiang J, Zhu W, Shi F, et al. Thick visual cortex in the early blind. J Neurosci 2009;29(7):2205-11.

[27] Silva PR, Farias T, Cascio F, et al. Neuroplasticity in visual impairments. Neurol Int 2018;10(4):7326.

[28] Burton H, Snyder AZ, Conturo TE, et al. Adaptive changes in early and late blind: an MRI study of Braille reading. J Neurophysiol 2002;87(1):589-607. 